\title{
Advance directives in oncology and haematology: a long way to go. A narrative review
}

\author{
Kevin Serey 1,6, Amélie Cambriel 2,6, Adrien Pollina-Bachelleriee, ${ }^{3,6}$ Jean-Pierre Lotz ${ }^{4,6}$, and François Philippart 5,6 * \\ 1 Anesthesiology and Intensive Care Medicine Department, APHP - Ambroise Paré University Hospital, \\ Boulogne-Billancourt, France ; kevin.serey@aphp.fr \\ 2 Anesthesiology and intensive Care Medicine Department, APHP-Tenon University Hospital, Paris, France; \\ amelie.cambriel@aphp.fr \\ 3 Anesthesia, Oncolope, Toulouse; adrien.pollina@iuct-oncopole.fr \\ 4 AP-HP, hôpitaux universitaires de l'Est Parisien,service d'oncologie médicale et de thérapie cellulaire, pôle \\ onco-hématologie ; e-mail@e-mail.com \\ 5 Medical and surgical intensive care unit, Groupe Hospitalier Paris Saint Joseph, 185 rue R. Losserand, \\ 75674, Paris, France; fphilippart@ghpsj.fr \\ 6 REQUIEM (Research / Reflexion on End of life support QUality In Everyday Medical practice) study group; \\ grouperequiem@gmail.com
}

* Correspondence: fphilippart@ghpsj.fr; Tel : +331 44123085

\begin{abstract}
Patients living with cancer often experience serious adverse events due to their condition or its treatments. Those events may lead to a critical care unit admission or even result in death. One of the most important but challenging part of care is to build a caring plan according to the patient's wishes, meeting his goals and values. Advance directives (ADs) allow everyone to give their preferences in advance regarding life sustaining treatments, continuation, and withdrawal or withholding of treatments in case one is not able to speak his mind anymore. While the absence of ADs is associated with a greater probability of receiving unwanted intensive care around the end of his life, their existence correlates with the respect of the patient's desires and his greater satisfaction. Although progress has been made to promote ADs' completion, they are still scarcely used among cancer patients in many countries. Several limitations to their acceptation and use can be detected. Efforts should be made to provide tailored solutions for the identified hindrances. This narrative review aims to depict the situation of ADs in the oncology context, and to highlight the future areas of improvement.
\end{abstract}

Keywords: End of Life; Advance Directives; Advance Care Planning; Intensive Care, Medical Oncology; malignant hemopathy

\section{Introduction}

Cancer is becoming more frequent as the population ages. An increase of $60 \%$ between now and 2040 is foreseen [1-3]. Although great therapeutics improvements have been made, cancer still remains a very severe condition. Both cancer and its treatments are responsible for patients' weakening [4,5], thereby sowing the seeds for acute illnesses and potential need for intensive care [6,7].

The major issue in such context is to define the potential relevance of critical care. Although the prognosis of intensive care unit (ICU) cancer patients has improved during the last decades (19), their mortality is very high [8,9], and residual morbidity is common among survivors $[4,10]$. Survival is associated with autonomy loss and psychological disorders [11], leading to severe impairments in patients' short and long term quality of life [12]. 
When ICU admission is debatable, the patient's opinion on life sustaining treatments, invasive care, possible alteration in autonomy and quality of life, should be at the centre of the decision-making process. Whether the expected benefits of intensive care are certain or not, this information should be obtained beforehand as patients should be given the possibility to accept the burden and possible consequences coming with invasive treatments.

Unfortunately, the severity of conditions requiring an ICU admission often goes along with consciousness' alterations and usually prevents patients from expressing their preferences and wishes. In such circumstances, physicians turn to relatives to gather as much information as possible regarding the patient's wishes. However, correlation with patients' thoughts is surprisingly poor $[13,14]$.

Lack of certainty about patients' outcome and preferences leads to wide variability in the assessment of critical care relevance between physicians [15]. This uncertainty may lead to a standby resuscitation allowing time to gather these elements. However, this standby resuscitation may be invasive and/or induce inadequate ICU admissions when end-of-life care would have been deemed more appropriate by patients and relatives [16]. Moreover, inappropriate aggressive care, although sometimes necessary while waiting for complementary information, is associated with worse patient quality of life and a higher risk of major depressive disorder in bereaved relatives [17].

Patients' preferences regarding care intensification and invasive treatments, as well as their beliefs, life and end-of-life goals, perceived health-related quality of life, along with medical reasoning, may help find the right balance between diagnostic or therapeutic procedures and patient comfort-oriented care.

In response to this imperative necessity, the concept of Advanced Directives (or Advance Care Planning (ACP) in English speaking countries) has been developed in the middle of the 20th century in the USA by Luis Kutner [18]. Since 1976, similar notions have been introduced in many national legislations, following the Californian initial momentum. Advanced care plans can gather any indication one deems to be important for his care. While the absence of ACP is associated with a greater probability of receiving unwanted intensive care, their existence is associated with better respect of patient's desires and greater satisfaction regarding received care [19].

In several studies around the world, patients reported a strong interest for AD or ACP [20-24]. Nonetheless, the percentage of people who effectively have AD remains very low in the general population $[25,26]$. It scarcely exceeds $50 \%$ of oncology or haematology patients in some North American reports [27-34] and may drop to $5 \%$ or less in other countries [35].

The aim of this review is to look at factors associated with the presence or absence of Advance Directives. We will look at factors depending on patients, the disease itself, physicians, as well as fears and misconceptions from both stakeholders (synthetize in figure 1).

\section{Patients}

Parameters associated with knowledge of $\mathrm{AD}$ by patients are synthetized in figure 2

\subsection{Demographic characteristics}

In multiple occidental studies, older age seemed to be directly correlated with the redaction of $\operatorname{AD}[23,25,30,33,36,37]$. It seems reasonable to suppose that older patients have a clearer idea of their end-of-life wishes and may be more prone to favor a good quality of life over a longer life. 
There is no other demographic parameter, such as gender, demonstrated to be linked to having $\mathrm{AD}[27,29,31]$.

\subsection{Education and social characteristics}

Socio-economic and educational background are highlighted as independent influencing factors in multiple works [36-40]. Both higher education and higher income are associated with the redaction of $\mathrm{AD}[27,41]$.

In a study conducted in an outpatient cancer clinic in Ohio, the authors suggested that people with low income and low educational background may have other concerns than discussing their preferences for treatment or end of life care, or that they may have less access to assistance or education programs on ACP [31,41]. However, a higher socioeconomic status is not constantly brought up as a favoring factor in the literature. On the contrary, a Korean study from 2017, while also finding an association between age or higher education and $\mathrm{AD}^{\prime}$ s redaction, revealed that participants with a low economic status were more willing to express themselves on end-of-life [42]. According to the authors, since people with a low economic status may feel more anxious about the future, AD could relieve part of those concerns.

The discordance between those different studies may be explained by the fact that the study populations come from very different cultures.

\subsection{Religious beliefs and traditions}

Religious beliefs may also impact AD. It is interesting to note that their influence varies depending on the countries and creeds [43].

In a Chinese study, having religious beliefs was associated with having AD [38], mostly because respondents considered that healthcare providers would not pay enough attention to their faith otherwise. Other studies found the same association between being Catholic, Jewish or Protestant, and AD's completion [44,45]. Even when religion is not associated with $\mathrm{AD}$ [46], spirituality does seem to favour reflection on health preferences as indicated in the study of Karches et al., where religiosity was not associated with AD's redaction, but with having designated a decision maker [47]. Interestingly, Maciejewski et al. found that positive religious coping (believing that God is going to help and support the patient through difficulties) was associated with less AD's completion, and a higher frequency of intensive care at the end of life [48]. Conversely, negative religious coping (considering that God has abandoned the patient and that the disease may be a punishment) was associated with higher $\mathrm{AD}^{\prime}$ s completion [48]. Thus, religion can affect in either direction patients' behaviour towards $\mathrm{AD}$, and more generally towards end-of-life goals of care (preference for early palliative care or aggressive treatments).

On the same note, a patient's culture also plays an important role [49]. In Eastern Asian cultures, burdening others is a disrespectful act, and talking about death is thought to bring bad luck on the person, therefore preventing an adequate prognosis disclosure and the expression of anticipated wishes. In China, where AD are perceived less favourably, the traditional family involvement in decisions on level of care leads to very few $\mathrm{AD}$ being written among cancer patients [38,50]. Such family influence in end-of-life care decisions also happens in occidental cultures [37,39,51].

Nonetheless, end-of-life care discussions between patients and their family, with or without counselling by a health-care worker, could improve AD's acceptance [42,50]. Furthermore, improvement in $\mathrm{AD}^{\prime}$ 's consideration is possible when vital prognosis is engaged, especially if patients refuse to undergo therapeutic intensification to favor comfort care [21]. 


\subsection{AD to relieve relatives}

Family plays a central role both during the process of writing $\mathrm{AD}$ and at the time of end-of-life decisions [52]. In an American study of 2008, 73\% of Latinos discussed ACP with their family but only $37 \%$ with their doctor [39]. They argued that writing ACP relieves their loved ones from making difficult decisions. Indeed, in the absence of AD, guilt or regret may push families to choose life-sustaining treatments over palliative care, no matter how aggressive and ineffective those treatments would be.

In a survey conducted in the USA, $63 \%$ of patients reported that completing AD avoided placing responsibility for end-of-life decision-making on their loved ones, even though all participants believed that their family or friend would be able to make adequate decisions by themselves [44].

\subsection{Awareness of advance directives}

Lack of awareness regarding AD is obviously a major obstacle. It ranges from complete ignorance of their existence or their usefulness, to redaction difficulties due to a lack of knowledge regarding their practical use or how to implement them.

Six years after AD's legal apparition, a French survey including 367 hospitalized patients revealed that only $34,8 \%$ of them were aware of the possibility to have some [20]. However, after proper information, $93 \%$ of the patients were in favor of $\mathrm{AD}$, suggesting that better communication could increase AD's drafting. The urge to solve this issue is underlined in McDonald's study where cancer patients themselves reported the lack of knowledge to be the strongest barrier to writing AD [27]. In Hubert's study, the need for more information was the reason why half the patients had not written their AD [33]. To raise awareness on $\mathrm{AD}$ and promote discussion with physicians or relatives, question prompt lists on end-of-life care seem to be efficient $[53,54]$.

People may also have trouble figuring out how their AD can specifically relate to their disease. In a survey conducted in Germany in 2014, half of the patients were in favour of AD consultations. However, only $20 \%$ reported that their interest for those consultations was associated with their cancer diagnosis [55]. This work underlines the necessity to properly inform patients and physicians on the role and use of $\mathrm{AD}$, and why a new serious disease may be a good time to think about one's wishes for his care.

\section{Sickness}

Suffering from a deadly disease compels patients to think about their end of life. Unsurprisingly, a new diagnosis of cancer and duration of the illness turn out to be favouring factors towards $\mathrm{AD}^{\prime}$ s writing $[21,29,55]$.

\subsection{The importance of prognosis}

Both the ongoing disease and the patient's past history play a role in the perception of AD. Sahm et al. noted in 2005 that patients having a previous experience of serious illness increasingly reported their intention to write AD [22]. In the same cohort, patients who often experienced pain as well as those deeming to be in a bad health state also reported more frequently their intention to draft $\mathrm{AD}$ [22].

Realizing the severity of one's condition seems to be a trigger to AD's drafting [50]. A longer self-assessed life-expectancy is associated with a lower likelihood of do-not-resuscitate order and a higher preference for life-prolonging over comfort-oriented care [56]. In a study including people without written $\mathrm{AD}$, the proportion of patients in favour of a specific consultation on $\mathrm{AD}$ doubled between those with a non-malignant disease and 
those with a malignant disease and a life expectancy shorter than 6 months [55]. Similar observations were made with curative treatments: patients who wrongly overestimated their survival rate were far more likely to favour life sustaining therapies care $[57,58]$.

However, even when prognosis is discussed with patients, it may not be well understood. A multicentre study including nearly six hundred metastatic cancer patients, revealed that even when informed of their prognosis by their physician, nearly a third of patients overestimated their life expectancy by more than 2 years. Correct recall of prognostic disclosure was associated with a more realistic assessment of their life expectancy [56].

\subsection{Mental stunning}

When information about the disease, its treatment and its prognosis is delivered during the cancer clinic visit, patients may be stunned, impairing their ability to process and understand those details [59]. Some may be concerned about the psychological repercussions for the patient of the announcement of a pejorative prognosis right after being informed of their diagnosis. However, George et al. found no lasting psychological harm amongst terminally ill patients after they understood their prognosis [60].

Addressing these psychological factors may help patients better understand the ins and outs of their care and therefore choose the most appropriate care [59].

\subsection{Link between end-of-life care and anticipated discussion}

Encouraging early communication between physicians and patients regarding the prognosis of the disease could help patients to better prepare for possible complications or tragic outcomes, and to refine their goal of care [61]. Many papers showed that patients who discussed their end-of-life preferences early in the history of their illness with their physicians were more likely to report a greater well-being, and to receive fewer aggressive interventions in their last weeks of life, without survival time reduction [62-64].

Ganti et al. retrospectively explored the relation between engagement in ACP amongst patients receiving a hematopoietic stem-cell transplantation (HSCT) and adverse outcomes, as well as overall survival. They found that patients who engaged in ACP before HSCT had a better one-year and overall survival compared with patients without ACP [29]. Though no direct causal relation could be suspected, it is possible that those who did not engage in $\mathrm{ACP}$ were less prepared to face complications when they occur.

\section{Healthcare workers: reluctance to provide information on AD}

As previously addressed, the absence of $\mathrm{AD}$ in the cancer patient population is partly due to the absence of information on this legal disposition. This lack of knowledge is partly due to the reluctance of clinicians to discuss patients' wishes [65].

In a study analysing discussions during medical appointments between advanced cancer patients and their oncologists, treatment was mentioned in $94,3 \%$ of visits whereas prognosis was only disclosed in 50,4\% of them [66]. Lower percentages of prognosis disclosure are underlined in other studies [67]. In extreme cases, this delay could lead to an absence of information about the severity of the prognosis until it is too late [68].

\subsection{Reluctance to discuss prognosis}

Many physicians feel inappropriately trained or prepared to talk about AD [65,69]. However, younger physicians are more prone to discuss AD sooner in the care $[70,71]$. 
Oncologists often feel responsible to initiate discussions about prognosis, but they believe that patients have to give them clues about what they are ready to hear [72]. While the absence of questions from patients may be interpreted as a wish to remain in the dark regarding their prognosis, [73], many patients expect physicians to raise the subject of end of life and ACP $[72,74,75]$ and figure that their doctor is not at ease with the matter since the subject is avoided [74]. To address the issue, Freedman offered an approach respecting the wish of patients to know or to not know: he suggested that physicians should "offer truth" and then respect the patient's choice [76].

\subsection{Fear of taking away hope}

Most oncologists feel that discussing end-of-life issues is emotionally difficult both for them and patients [65]. Indeed, patients seek hope and reassurance from their physicians as they "go to an oncologist to be cured, not to be buried" [77]. Physicians may postpone raising the subject as they sometimes fear that talking about death will be perceived by the patient as an indirect message that he is dying, thus triggering worries and fears [78] and possibly deteriorating the doctor-patient relationship [79]. However, focusing only on treatments may jeopardize opening discussion about end-of-life issues [65].

Several studies suggest that it is possible to talk about end-of-life preferences and write AD without interfering with the patient's hope [53,80-82]. AD can even help terminally ill patients to reach a sense of control and peace of mind [82]. Moreover, since prognosis is almost impossible to determine with certainty at the time of diagnosis and may improve over time thanks to new treatments and study protocols [83], prognosis estimations should be refined over time, therefore initially authorizing the patient for hope [84].

\subsection{Finding the right timing}

Despite a general agreement on the necessity of $\mathrm{AD}$ [40], the best timing to write them is a matter of debate. Some physicians report they are uncomfortable treating and implementing palliative care for a patient at the same time, as it may seem contradictory [65]. They think that the best timing to start a discussion on end-of-life issues and AD is when the patient becomes terminally ill $[40,70,79]$.

Delaying the discussion may not ease the process: when there is no curative option left, the change in goal of care is even more abrupt and causes more distress [85]. Postponing ACP discussions until patients seem ready or ask for it is probably not the best alternative either as most patients will wait, preferring their doctor to break the subject $[74,86,87]$.

Patients themselves reported that AD completion or dedicated consultations should take place early in the illness [40]. Indeed, early discussion of goals of care probably remains the best way to provide a person-centered care throughout follow-ups. Waiting for patients' acceptance while periodically reminding them to think about AD could be part of the solution $[88,89]$.

\subsection{Time consumption}

Lack of time during oncology consultations is an identified barrier to end-of-life care discussion and AD's completion [55,78]. In a British study, one third of patients reported that they lacked time during clinic appointments to discuss AD [74].

Distilling prognosis and end-of-life information throughout the follow-up may be less time-consuming, could favour discussion, and may strengthen the patient-physician relationship, therefore giving patients a better chance to express their desires regarding their care [85]. 


\section{5. / Fear of misuse}

Some obstacles to the realization of $\mathrm{AD}$ are due to physicians and patients' misbeliefs or fears [90].

Some patients think that $\mathrm{AD}$ are dangerous because they may become inadequate in an unplanned acute situation [91]. They fear that AD could dictate the physicians' role, thus leading to less invasive care regardless of the context $[22,91]$. This underlines a lack of information on AD in three ways: practical use of this tool, possibility to modify AD at any time, as well as their integration in the healthcare reflection.

Other patients worry that their wishes may not be respected [22], as it was underlined for Do Not Resuscitate (DNR) orders [92]. However, the first reason for AD transgression may just be the ignorance of their existence [92]. In the USA, the Physician Orders for Life-Sustaining Treatment (POLST) program recommends to always keep a copy of the patient's form that should follow him in case of a hospital transfer for example [93]. However, this is not a foolproof method either, and the lack of interoperability between electronic health records in various facilities is a problem still to resolve [94].

Another barrier to AD is the fear of coercion. Sahm et al. explored this concern amongst patients, healthy controls, nursing staff and physicians [22]. They found that more than half of the participants in all groups worried that patients could be pressured to write AD. However, although AD remains optional, it is important to keep in mind that many patients also identify AD as a facilitator to discuss end of life care [37] and that they have proven to foster tailored care and to improve patients' quality of end-of-life [95].

\section{Discussion: how to improve $\mathrm{AD}^{\prime}$ s generalization?}

$\mathrm{AD}$ are an effective tool to improve the quality of terminally ill patients' end-of-life. In a systematic review, Arianne Brinckman-Stoppelenburg highlighted an improvement in quality of life for both patients and their family, a higher compliance with patients' preferences, and a decreased use of aggressive care at the benefit of palliative care when AD were redacted [95].

\subsection{AD for who?}

Overall, despites multiple attempts to identify favourable or unfavourable factors to the completion of $\mathrm{AD}$, it is difficult to recognize patients who would most benefit from AD's drafting.

First, we ought to understand that patients may not want to choose in advance which treatments they will seek or reject in the future, and that they may prefer to rely on their relatives or caregivers. This ultimate expression of autonomy is summarized by MeganJane Johnstone as "the choice to not have to choose" [96].

As stated by Stephanie Johnson, "individual autonomy is socially dependent" [97]. The priority is to concentrate on the meaning each patient gives to his illness, on his preferences for his life and end-of-life. AD should not be just a mandatory list of dos and don'ts kept in medical records.

If patients are strongly opposed to writing $\mathrm{AD}$, both having named a health care surrogate and having previously collected information about their wishes are valuable. Discussing $\mathrm{AD}$ does not necessarily mean writing $\mathrm{AD}$, but it launches the reflexion process and favours the discussions.

\subsection{Discussing AD: with who?}


In an American study amongst cancer patients, $77 \%$ had discussed AD with their relatives and only $41 \%$ with a physician [23]. Moreover, only $22 \%$ of those who discussed them with a physician did so with their treating oncologist [23]. Besides, among those who had not previously discussed AD with their oncologist, only $23 \%$ reported they would like to do so. It seemed inconsistent for many of them to talk about death, palliative care and discontinuation of treatment while being actively treated by the same oncologist [23]. Ironically, almost all patients were in favour of a policy in which patients would discuss AD with their admitting physician, even if they never met him before [23].

In many studies, patients would rather talk about AD with their general practitioner $[23,33,79]$. In a certain way it makes sense as it is usually the physician who knows the patient best [23]. However, the primary care physician may not always be the best interlocutor to help the patient face his specific malignant disease and possible complications. Yet, multiplying the range of health care correspondents allows for different perspectives on the subject, and also improves AD's completion [32,98].

As previously mentioned, another pragmatic issue is the available time during oncological appointments. Thus, having other opportunities to discuss their goal of care may enhance patients' participation in AD. Trained nurses can sensitize patients, either through question prompt lists or during non-scripted interviews they can handle in dedicated consultation [28,89]. Clinicians themselves considered it acceptable for all health workers to engage in goal of care discussions [70,99,100]. Having an advanced practice provider specifically initiate AD discussions seems to be effective [101].

\subsection{What to discuss and how to write?}

It is rather easy to realize how complex it could be for a patient to write their AD: they ignore what specific situation they will have to face, or how their document will be construed. Adding to the complexity of the exercise, patients can have difficulties understanding limitations and consequences of life-sustaining therapies [99].

The different information and wishes expressed by patients will probably not fit a restrictive questionnaire: a standardized form may be impersonal thus inappropriate. In a study involving general practitioners, they underlined how AD is about life and death and figuring out the patient's wants and needs, and "that can't be too calculated or tick boxed" [79].

Contrary to DNR orders, AD should allow a great freedom of thought. There, patients can express all the complexity of the personal, material, spiritual and social aspects of their plan of care. Moreover, AD still enable the expression of hope while preparing for the end-of-life, whereas DNR are deemed "blunt" or "without any empathy" by patients [102]. It is then important to leave blank spaces in AD forms for unrestricted expression of the patient's wishes.

\subsection{And then...}

In a recent literature review, Pedro Grachinski Buiar and José Roberto Goldim identified five steps in the path of an $\mathrm{AD}$ : discussion, composition, registration, access and implementation [103]. Each of these steps have its own barriers that have been explored in our review. We suggest adding a sixth step which is reassessment as AD are a cyclic process, constantly in evolution.

\section{Conclusions}

$\mathrm{AD}$ and, more broadly, ACP are arrangements that allow patients to express their preferences regarding their therapeutic management, particularly in situations of chronic 
pathology where acute deterioration is always possible. Beyond choices regarding care, organ support or specific procedures, these arrangements can define the patient's life values. More than just a written record of the specific elements that the person is likely to accept or refuse, AD and ACP should be a tool for reflection and an opportunity for a physician-patient exchange regarding the patient's philosophy in order to improve the personalization of care. In spite of the steps taken, the use of AD remains very insufficient, especially in Europe, and this fact should encourage us to continue our efforts to both increase their application and to extend their scope of use.

The early stage of reflection allows us to approach the subject with more distance and more general and less immediate questions

\subsection{Figure}

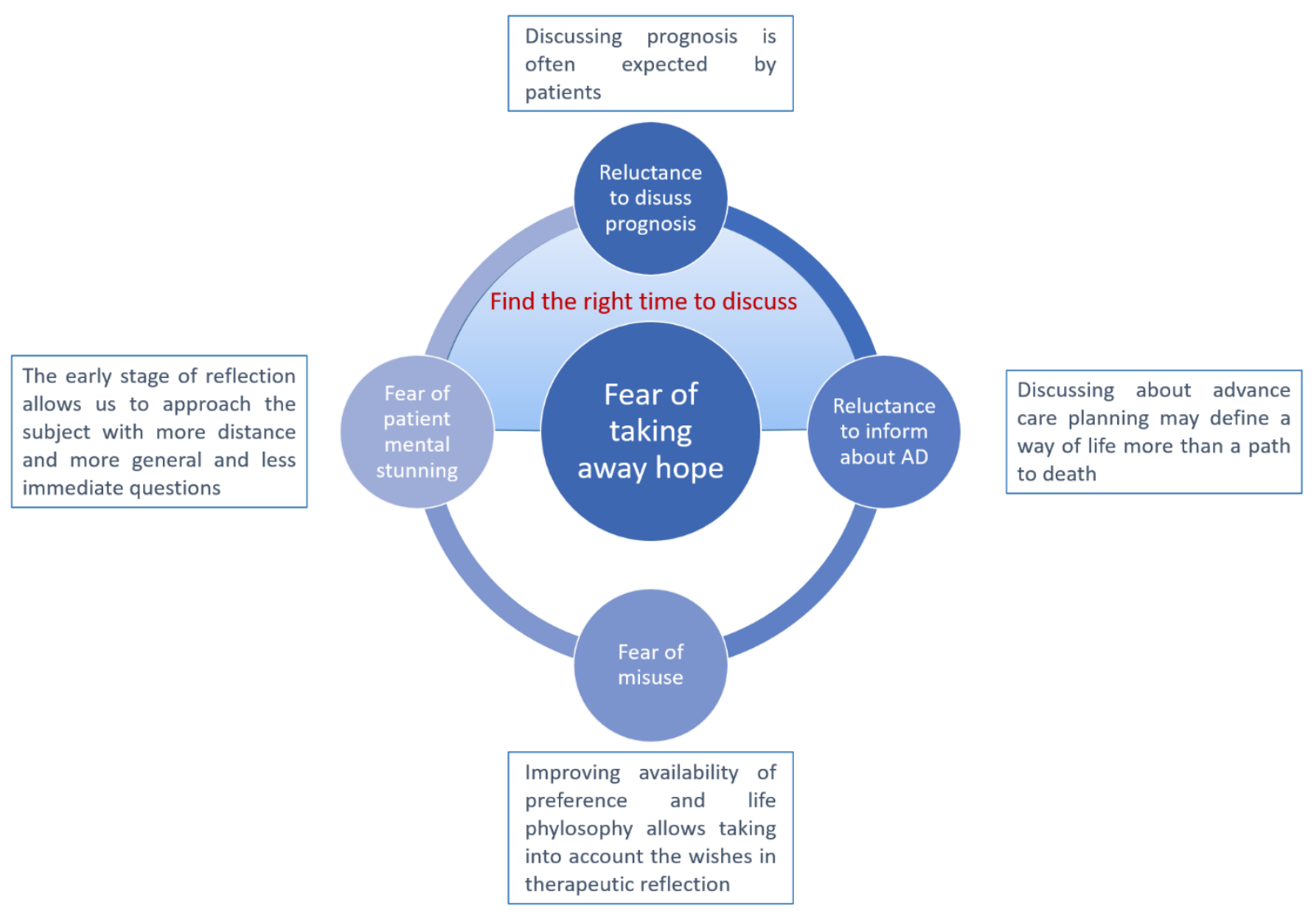


Figure 1 : Main obstacle for AD information and use in cancer patients

Figure 2 : Main parameters associated with knowledge of advance directives

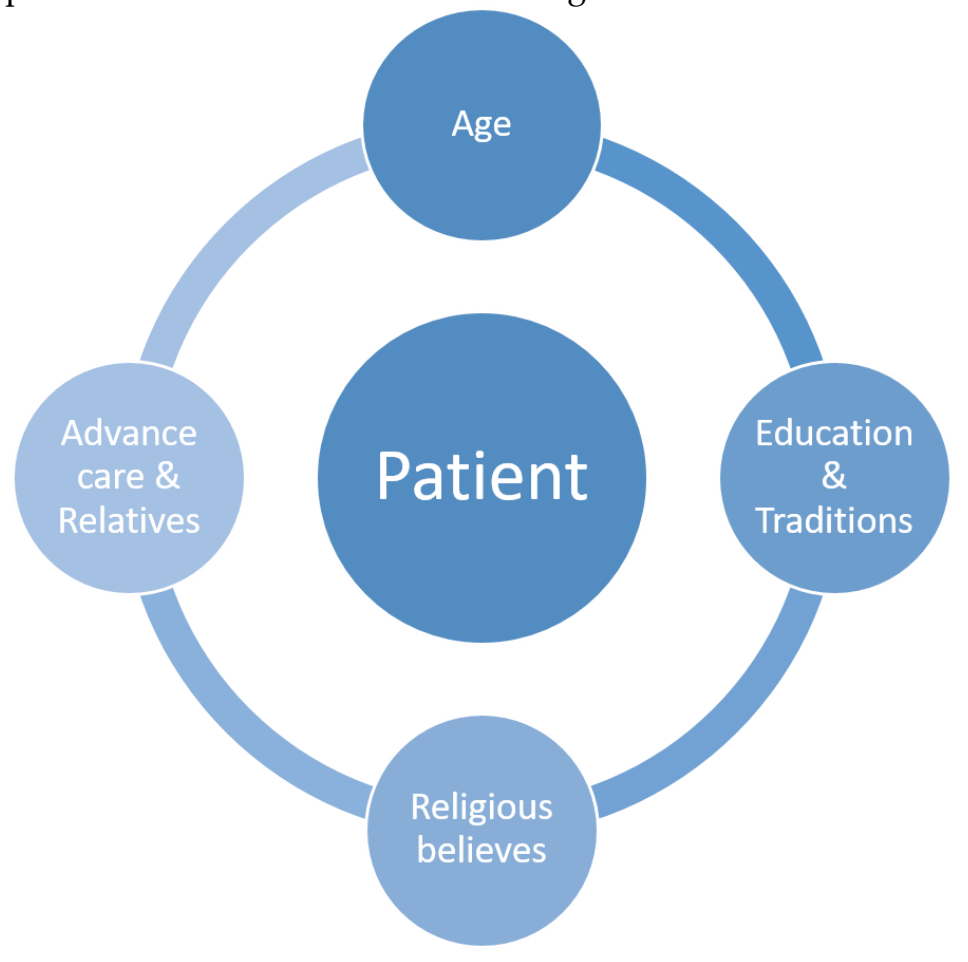

Author Contributions:

Conceptualization, KS and AC and FP. Methodology, FP. Validation, FP and JPL. Original draft preparation, FP and KS and AC. writing - review and editing: FP, JPL and APB. All authors have read and agreed to the published version of the manuscript.

Funding: none.

Institutional Review Board Statement: Not applicable

Informed Consent Statement: Not applicable.

Data Availability Statement: Not applicable

Acknowledgments: In this section, you can acknowledge any support given which is not covered by the author contribution or funding sections. This may include administrative and technical support, or donations in kind (e.g., materials used for experiments).

Conflicts of Interest: “The authors declare no conflict of interest."

\section{References}

1. Miller, K.D.; Siegel, R.L.; Lin, C.C.; Mariotto, A.B.; Kramer, J.L.; Rowland, J.H.; Stein, K.D.; Alteri, R.; Jemal, A. Cancer Treatment and Survivorship Statistics, 2016. CA. Cancer J. Clin. 2016, 66, 271-289, doi:10.3322/caac.21349.

2. Quaresma, M.; Coleman, M.P.; Rachet, B. 40-Year Trends in an Index of Survival for All Cancers Combined and Survival Adjusted for Age and Sex for Each Cancer in England and Wales, 1971-2011: A Population-Based Study. Lancet Lond. Engl. 2015, 385, 1206-1218, doi:10.1016/S0140-6736(14)61396-9.

3. Soerjomataram, I.; Lortet-Tieulent, J.; Parkin, D.M.; Ferlay, J.; Mathers, C.; Forman, D.; Bray, F. Global Burden of Cancer in 2008: A Systematic Analysis of Disability-Adjusted Life-Years in 12 World Regions. Lancet Lond. Engl. 2012, 380, 1840-1850, doi:10.1016/S0140-6736(12)60919-2.

4. Meert, A.-P.; Grigoriu, B.; Licker, M.; Van Schil, P.E.; Berghmans, T. Intensive Care in Thoracic Oncology. Eur. Respir. J. 2017, 49, doi:10.1183/13993003.02189-2016.

5. Falanga, A.; Russo, L.; Milesi, V.; Vignoli, A. Mechanisms and Risk Factors of Thrombosis in Cancer. Crit. Rev. Oncol. Hematol. 2017, 118, 79-83, doi:10.1016/j.critrevonc.2017.08.003. 
6. Maschmeyer, G.; Bertschat, F.-L.; Moesta, K.T.; Häusler, E.; Held, T.K.; Nolte, M.; Osterziel, K.-J.; Papstein, V.; Peters, M.; Reich, G.; et al. Outcome Analysis of 189 Consecutive Cancer Patients Referred to the Intensive Care Unit as Emergencies during a 2Year Period. Eur. J. Cancer Oxf. Engl. 1990 2003, 39, 783-792, doi:10.1016/s0959-8049(03)00004-2.

7. Soares, M.; Caruso, P.; Silva, E.; Teles, J.M.M.; Lobo, S.M.A.; Friedman, G.; Dal Pizzol, F.; Mello, P.V.C.; Bozza, F.A.; Silva, U.V.A.; et al. Characteristics and Outcomes of Patients with Cancer Requiring Admission to Intensive Care Units: A Prospective Multicenter Study. Crit. Care Med. 2010, 38, 9-15, doi:10.1097/CCM.0b013e3181c0349e.

8. Lecuyer, L.; Chevret, S.; Thiery, G.; Darmon, M.; Schlemmer, B.; Azoulay, E. The ICU Trial: A New Admission Policy for Cancer Patients Requiring Mechanical Ventilation. Crit. Care Med. 2007, 35, 808-814, doi:10.1097/01.CCM.0000256846.27192.7A.

9. Azoulay, E.; Mokart, D.; Pène, F.; Lambert, J.; Kouatchet, A.; Mayaux, J.; Vincent, F.; Nyunga, M.; Bruneel, F.; Laisne, L.-M.; et al. Outcomes of Critically Ill Patients with Hematologic Malignancies: Prospective Multicenter Data from France and Belgium-a Groupe de Recherche Respiratoire En Réanimation Onco-Hématologique Study. J. Clin. Oncol. Off. J. Am. Soc. Clin. Oncol. 2013, 31, 2810-2818, doi:10.1200/JCO.2012.47.2365.

10. Vincent, F.; Soares, M.; Mokart, D.; Lemiale, V.; Bruneel, F.; Boubaya, M.; Gonzalez, F.; Cohen, Y.; Azoulay, E.; Darmon, M. InHospital and Day-120 Survival of Critically Ill Solid Cancer Patients after Discharge of the Intensive Care Units: Results of a Retrospective Multicenter Study-A Groupe de Recherche Respiratoire En Réanimation En Onco-Hématologie (Grrr-OH) Study. Ann. Intensive Care 2018, 8, doi:10.1186/s13613-018-0386-6.

11. Hashem, M.D.; Nallagangula, A.; Nalamalapu, S.; Nunna, K.; Nausran, U.; Robinson, K.A.; Dinglas, V.D.; Needham, D.M.; Eakin, M.N. Patient Outcomes after Critical Illness: A Systematic Review of Qualitative Studies Following Hospital Discharge. Crit. Care Lond. Engl. 2016, 20, 345, doi:10.1186/s13054-016-1516-x.

12. Oeyen, S.G.; Benoit, D.D.; Annemans, L.; Depuydt, P.O.; Van Belle, S.J.; Troisi, R.I.; Noens, L.A.; Pattyn, P.; Decruyenaere, J.M. Long-Term Outcomes and Quality of Life in Critically Ill Patients with Hematological or Solid Malignancies: A Single Center Study. Intensive Care Med. 2013, 39, 889-898, doi:10.1007/s00134-012-2791-x.

13. Hofhuis, J.G.M.; Spronk, P.E.; van Stel, H.F.; Schrijvers, G.J.P.; Rommes, J.H.; Bakker, J. The Impact of Critical Illness on Perceived Health-Related Quality of Life during ICU Treatment, Hospital Stay, and after Hospital Discharge: A Long-Term Followup Study. Chest 2008, 133, 377-385, doi:10.1378/chest.07-1217.

14. Hofhuis, J.; Hautvast, J.L.A.; Schrijvers, A.J.P.; Bakker, J. Quality of Life on Admission to the Intensive Care: Can We Query the Relatives? Intensive Care Med. 2003, 29, 974-979, doi:10.1007/s00134-003-1763-6.

15. Garrouste-Orgeas, M.; Tabah, A.; Vesin, A.; Philippart, F.; Kpodji, A.; Bruel, C.; Grégoire, C.; Max, A.; Timsit, J.F.; Misset, B. The ETHICA Study (Part II): Simulation Study of Determinants and Variability of ICU Physician Decisions in Patients Aged 80 or Over. Intensive Care Med. 2013, 39, 1574-1583, doi:10.1007/s00134-013-2977-x.

16. Mack, J.W.; Cronin, A.; Keating, N.L.; Taback, N.; Huskamp, H.A.; Malin, J.L.; Earle, C.C.; Weeks, J.C. Associations between End-of-Life Discussion Characteristics and Care Received near Death: A Prospective Cohort Study. J. Clin. Oncol. Off. J. Am. Soc. Clin. Oncol. 2012, 30, 4387-4395, doi:10.1200/JCO.2012.43.6055.

17. Sato, T.; Soejima, K.; Fujisawa, D.; Takeuchi, M.; Arai, D.; Nakachi, I.; Naoki, K.; Kawada, I.; Yasuda, H.; Ishioka, K.; et al. Prognostic Understanding at Diagnosis and Associated Factors in Patients with Advanced Lung Cancer and Their Caregivers. The Oncologist 2018, 23, 1218-1229, doi:10.1634/theoncologist.2017-0329.

18. Kutner, L. The Living Will: Coping with the Historical Event of Death. Bayl. Law Rev. 1975, 27, 39-53.

19. Silveira, M.J.; Kim, S.Y.H.; Langa, K.M. Advance Directives and Outcomes of Surrogate Decision Making before Death. N. Engl. J. Med. 2010, 362, 1211-1218, doi:10.1056/NEJMsa0907901.

20. Guyon, G.; Garbacz, L.; Baumann, A.; Bohl, E.; Maheut-Bosser, A.; Coudane, H.; Kanny, G.; Gillois, P.; Claudot, F. Trusted person and living will: information and implementation defect. Rev. Med. Interne 2014, 35, 643-648, doi:10.1016/j.revmed.2013.10.331.

21. Zhang, Q.; Xie, C.; Xie, S.; Liu, Q. The Attitudes of Chinese Cancer Patients and Family Caregivers toward Advance Directives. Int. J. Environ. Res. Public. Health 2016, 13, doi:10.3390/ijerph13080816.

22. Sahm, S.; Will, R.; Hommel, G. Attitudes towards and Barriers to Writing Advance Directives amongst Cancer Patients, Healthy Controls, and Medical Staff. J. Med. Ethics 2005, 31, 437-440, doi:10.1136/jme.2004.009605.

23. Dow, L.A.; Matsuyama, R.K.; Ramakrishnan, V.; Kuhn, L.; Lamont, E.B.; Lyckholm, L.; Smith, T.J. Paradoxes in Advance Care Planning: The Complex Relationship of Oncology Patients, Their Physicians, and Advance Medical Directives. J. Clin. Oncol. Off. J. Am. Soc. Clin. Oncol. 2010, 28, 299-304, doi:10.1200/JCO.2009.24.6397.

24. Mercadante, S.; Costanzi, A.; Marchetti, P.; Casuccio, A. Attitudes Among Patients With Advanced Cancer Toward Euthanasia and Living Wills. J. Pain Symptom Manage. 2016, 51, e3-6, doi:10.1016/j.jpainsymman.2016.01.001.

25. De Vleminck, A.; Pardon, K.; Houttekier, D.; Van den Block, L.; Vander Stichele, R.; Deliens, L. The Prevalence in the General Population of Advance Directives on Euthanasia and Discussion of End-of-Life Wishes: A Nationwide Survey. BMC Palliat. Care 2015, 14, 71, doi:10.1186/s12904-015-0068-1.

26. Pennec, S.; Monnier, A.; Pontone, S.; Aubry, R. End-of-Life Medical Decisions in France: A Death Certificate Follow-up Survey 5 Years after the 2005 Act of Parliament on Patients' Rights and End of Life. BMC Palliat. Care 2012, 11, 25, doi:10.1186/1472-684X-11-25.

27. McDonald, J.C.; du Manoir, J.M.; Kevork, N.; Le, L.W.; Zimmermann, C. Advance Directives in Patients with Advanced Cancer Receiving Active Treatment: Attitudes, Prevalence, and Barriers. Support. Care Cancer Off. J. Multinatl. Assoc. Support. Care Cancer 2017, 25, 523-531, doi:10.1007/s00520-016-3433-6. 
28. Obel, J.; Brockstein, B.; Marschke, M.; Robicsek, A.; Konchak, C.; Sefa, M.; Ziomek, N.; Benfield, T.; Peterson, C.; Gustafson, C.; et al. Outpatient Advance Care Planning for Patients with Metastatic Cancer: A Pilot Quality Improvement Initiative. J. Palliat. Med. 2014, 17, 1231-1237, doi:10.1089/jpm.2014.0085.

29. Ganti, A.K.; Lee, S.J.; Vose, J.M.; Devetten, M.P.; Bociek, R.G.; Armitage, J.O.; Bierman, P.J.; Maness, L.J.; Reed, E.C.; Loberiza, F.R. Outcomes after Hematopoietic Stem-Cell Transplantation for Hematologic Malignancies in Patients with or without Advance Care Planning. J. Clin. Oncol. Off. J. Am. Soc. Clin. Oncol. 2007, 25, 5643-5648, doi:10.1200/JCO.2007.11.1914.

30. Tan, T.S.; Jatoi, A. An Update on Advance Directives in the Medical Record: Findings from 1186 Consecutive Patients with Unresectable Exocrine Pancreas Cancer. J. Gastrointest. Cancer 2008, 39, 100-103, doi:10.1007/s12029-008-9041-z.

31. Ho, G.W.K.; Skaggs, L.; Yenokyan, G.; Kellogg, A.; Johnson, J.A.; Lee, M.C.; Heinze, K.; Hughes, M.T.; Sulmasy, D.P.; Kub, J.; et al. Patient and Caregiver Characteristics Related to Completion of Advance Directives in Terminally Ill Patients. Palliat. Support. Care 2017, 15, 12-19, doi:10.1017/S147895151600016X.

32. Clark, M.A.; Ott, M.; Rogers, M.L.; Politi, M.C.; Miller, S.C.; Moynihan, L.; Robison, K.; Stuckey, A.; Dizon, D. Advance Care Planning as a Shared Endeavor: Completion of ACP Documents in a Multidisciplinary Cancer Program. Psychooncology. 2017, 26, 67-73, doi:10.1002/pon.4010.

33. Hubert, E.; Schulte, N.; Belle, S.; Gerhardt, A.; Merx, K.; Hofmann, W.-K.; Stein, A.; Burkholder, I.; Hofheinz, R.-D.; Kripp, M. Cancer Patients and Advance Directives: A Survey of Patients in a Hematology and Oncology Outpatient Clinic. Onkologie 2013, 36, 398-402, doi:10.1159/000353604.

34. Ha, F.J.; Weickhardt, A.J.; Parakh, S.; Vincent, A.D.; Glassford, N.J.; Warrillow, S.; Jones, D. Survival and Functional Outcomes of Patients with Metastatic Solid Organ Cancer Admitted to the Intensive Care Unit of a Tertiary Centre. Crit. Care Resusc. J. Australas. Acad. Crit. Care Med. 2017, 19, 159-166.

35. Roger, C.; Morel, J.; Molinari, N.; Orban, J.C.; Jung, B.; Futier, E.; Desebbe, O.; Friggeri, A.; Silva, S.; Bouzat, P.; et al. Practices of End-of-Life Decisions in 66 Southern French ICUs 4 Years after an Official Legal Framework: A 1-Day Audit. Anaesth. Crit. Care Pain Med. 2015, 34, 73-77, doi:10.1016/j.accpm.2014.10.001.

36. Brown, A.J.; Shen, M.J.; Urbauer, D.; Taylor, J.; Parker, P.A.; Carmack, C.; Prescott, L.; Kolawole, E.; Rosemore, C.; Sun, C.; et al. Room for Improvement: An Examination of Advance Care Planning Documentation among Gynecologic Oncology Patients. Gynecol. Oncol. 2016, 142, 525-530, doi:10.1016/j.ygyno.2016.07.010.

37. van Oorschot, B.; Schuler, M.; Simon, A.; Flentje, M. Advance Directives: Prevalence and Attitudes of Cancer Patients Receiving Radiotherapy. Support. Care Cancer Off. J. Multinatl. Assoc. Support. Care Cancer 2012, 20, 2729-2736, doi:10.1007/s00520-012-1394-y.

38. Zheng, R.-J.; Fu, Y.; Xiang, Q.-F.; Yang, M.; Chen, L.; Shi, Y.-K.; Yu, C.-H.; Li, J.-Y. Knowledge, Attitudes, and Influencing Factors of Cancer Patients toward Approving Advance Directives in China. Support. Care Cancer Off. J. Multinatl. Assoc. Support. Care Cancer 2016, 24, 4097-4103, doi:10.1007/s00520-016-3223-1.

39. Sudore, R.L.; Schickedanz, A.D.; Landefeld, C.S.; Williams, B.A.; Lindquist, K.; Pantilat, S.Z.; Schillinger, D. Engagement in Multiple Steps of the Advance Care Planning Process: A Descriptive Study of Diverse Older Adults. J. Am. Geriatr. Soc. 2008, 56, 1006-1013, doi:10.1111/j.1532-5415.2008.01701.x.

40. Keam, B.; Yun, Y.H.; Heo, D.S.; Park, B.W.; Cho, C.-H.; Kim, S.; Lee, D.H.; Lee, S.N.; Lee, E.S.; Kang, J.H.; et al. The Attitudes of Korean Cancer Patients, Family Caregivers, Oncologists, and Members of the General Public toward Advance Directives. Support. Care Cancer Off. J. Multinatl. Assoc. Support. Care Cancer 2013, 21, 1437-1444, doi:10.1007/s00520-0121689-z.

41. Kelley, C.G.; Lipson, A.R.; Daly, B.J.; Douglas, S.L. Advance Directive Use and Psychosocial Characteristics: An Analysis of Patients Enrolled in a Psychosocial Cancer Registry. Cancer Nurs. 2009, 32, 335-341, doi:10.1097/NCC.0b013e3181a52510.

42. Lee, J.E.; Shin, D.W.; Son, K.Y.; Park, H.J.; Lim, J.-Y.; Song, M.S.; Park, Y.-H.; Cho, B. Factors Influencing Attitudes toward Advance Directives in Korean Older Adults. Arch. Gerontol. Geriatr. 2018, 74, 155-161, doi:10.1016/j.archger.2017.10.008.

43. Chakraborty, R.; El-Jawahri, A.; Litzow, M.R.; Syrjala, K.L.; Parnes, A.D.; Hashmi, S.K. A Systematic Review of Religious Beliefs about Major End-of-Life Issues in the Five Major World Religions. Palliat. Support. Care 2017, 15, 609-622, doi:10.1017/S1478951516001061.

44. Alano, G.J.; Pekmezaris, R.; Tai, J.Y.; Hussain, M.J.; Jeune, J.; Louis, B.; El-Kass, G.; Ashraf, M.S.; Reddy, R.; Lesser, M.; et al. Factors Influencing Older Adults to Complete Advance Directives. Palliat. Support. Care 2010, 8, 267-275, doi:10.1017/S1478951510000064.

45. Hoe, D.F.; Enguidanos, S. So Help Me, God: Religiosity and End-of-Life Choices in a Nationally Representative Sample. J. Palliat. Med. 2020, 23, 563-567, doi:10.1089/jpm.2019.0209.

46. Sharp, S.; Carr, D.; Macdonald, C. Religion and End-of-Life Treatment Preferences: Assessing the Effects of Religious Denomination and Beliefs. Soc. Forces 2012, 91, 275-298, doi:10.1093/sf/sos061.

47. Karches, K.E.; Chung, G.S.; Arora, V.; Meltzer, D.O.; Curlin, F.A. Religiosity, Spirituality, and End-of-Life Planning: A Single-Site Survey of Medical Inpatients. J. Pain Symptom Manage. 2012, 44, 843-851, doi:10.1016/j.jpainsymman.2011.12.277.

48. Maciejewski, P.K.; Phelps, A.C.; Kacel, E.L.; Balboni, T.A.; Balboni, M.; Wright, A.A.; Pirl, W.; Prigerson, H.G. Religious Coping and Behavioral Disengagement: Opposing Influences on Advance Care Planning and Receipt of Intensive Care near Death. Psychooncology. 2012, 21, 714-723, doi:10.1002/pon.1967.

49. Wallace, C.L. Family Communication and Decision Making at the End of Life: A Literature Review. Palliat. Support. Care 2015, 13, 815-825, doi:10.1017/S1478951514000388. 
50. Wong, S.Y.; Lo, S.H.; Chan, C.H.; Chui, H.S.; Sze, W.K.; Tung, Y. Is It Feasible to Discuss an Advance Directive with a Chinese Patient with Advanced Malignancy? A Prospective Cohort Study. Hong Kong Med. J. Xianggang Yi Xue Za Zhi 2012, $18,178-185$.

51. McPherson, C.J.; Wilson, K.G.; Murray, M.A. Feeling like a Burden to Others: A Systematic Review Focusing on the End of Life. Palliat. Med. 2007, 21, 115-128, doi:10.1177/0269216307076345.

52. Puchalski, C.M.; Zhong, Z.; Jacobs, M.M.; Fox, E.; Lynn, J.; Harrold, J.; Galanos, A.; Phillips, R.S.; Califf, R.; Teno, J.M. Patients Who Want Their Family and Physician to Make Resuscitation Decisions for Them: Observations from SUPPORT and HELP. Study to Understand Prognoses and Preferences for Outcomes and Risks of Treatment. Hospitalized Elderly Longitudinal Project. J. Am. Geriatr. Soc. 2000, 48, S84-90, doi:10.1111/j.1532-5415.2000.tb03146.x.

53. Clayton, J.M.; Butow, P.N.; Tattersall, M.H.N.; Devine, R.J.; Simpson, J.M.; Aggarwal, G.; Clark, K.J.; Currow, D.C.; Elliott, L.M.; Lacey, J.; et al. Randomized Controlled Trial of a Prompt List to Help Advanced Cancer Patients and Their Caregivers to Ask Questions about Prognosis and End-of-Life Care. J. Clin. Oncol. Off. J. Am. Soc. Clin. Oncol. 2007, 25, 715-723, doi:10.1200/JCO.2006.06.7827.

54. Dimoska, A.; Tattersall, M.H.N.; Butow, P.N.; Shepherd, H.; Kinnersley, P. Can a “Prompt List” Empower Cancer Patients to Ask Relevant Questions? Cancer 2008, 113, 225-237, doi:10.1002/cncr.23543.

55. Pfirstinger, J.; Kattner, D.; Edinger, M.; Andreesen, R.; Vogelhuber, M. The Impact of a Tumor Diagnosis on Patients' Attitudes toward Advance Directives. Oncology 2014, 87, 246-256, doi:10.1159/000363508.

56. Enzinger, A.C.; Zhang, B.; Schrag, D.; Prigerson, H.G. Outcomes of Prognostic Disclosure: Associations With Prognostic Understanding, Distress, and Relationship With Physician Among Patients With Advanced Cancer. J. Clin. Oncol. Off. J. Am. Soc. Clin. Oncol. 2015, 33, 3809-3816, doi:10.1200/JCO.2015.61.9239.

57. Weeks, J.C.; Cook, E.F.; O’Day, S.J.; Peterson, L.M.; Wenger, N.; Reding, D.; Harrell, F.E.; Kussin, P.; Dawson, N.V.; Connors, A.F.; et al. Relationship between Cancer Patients' Predictions of Prognosis and Their Treatment Preferences. JAMA 1998, 279, 1709-1714, doi:10.1001/jama.279.21.1709.

58. Sborov, K.; Giaretta, S.; Koong, A.; Aggarwal, S.; Aslakson, R.; Gensheimer, M.F.; Chang, D.T.; Pollom, E.L. Impact of Accuracy of Survival Predictions on Quality of End-of-Life Care Among Patients With Metastatic Cancer Who Receive Radiation Therapy. J. Oncol. Pract. 2019, 15, e262-e270, doi:10.1200/JOP.18.00516.

59. Derry, H.M.; Reid, M.C.; Prigerson, H.G. Advanced Cancer Patients' Understanding of Prognostic Information: Applying Insights from Psychological Research. Cancer Med. 2019, 8, 4081-4088, doi:10.1002/cam4.2331.

60. George, L.S.; Maciejewski, P.K.; Epstein, A.S.; Shen, M.; Prigerson, H.G. Advanced Cancer Patients' Changes in Accurate Prognostic Understanding and Their Psychological Well-Being. J. Pain Symptom Manage. 2020, 59, 983-989, doi:10.1016/j.jpainsymman.2019.12.366.

61. Yoo, S.H.; Lee, J.; Kang, J.H.; Maeng, C.H.; Kim, Y.J.; Song, E.-K.; Koh, Y.; Yun, H.-J.; Shim, H.-J.; Kwon, J.H.; et al. Association of Illness Understanding with Advance Care Planning and End-of-Life Care Preferences for Advanced Cancer Patients and Their Family Members. Support. Care Cancer 2020, 28, 2959-2967, doi:10.1007/s00520-019-05174-5.

62. Temel, J.S.; Greer, J.A.; Muzikansky, A.; Gallagher, E.R.; Admane, S.; Jackson, V.A.; Dahlin, C.M.; Blinderman, C.D.; Jacobsen, J.; Pirl, W.F.; et al. Early Palliative Care for Patients with Metastatic Non-Small-Cell Lung Cancer. N. Engl. J. Med. 2010, 363, 733-742, doi:10.1056/NEJMoa1000678.

63. Greer, J.A.; Pirl, W.F.; Jackson, V.A.; Muzikansky, A.; Lennes, I.T.; Heist, R.S.; Gallagher, E.R.; Temel, J.S. Effect of Early Palliative Care on Chemotherapy Use and End-of-Life Care in Patients With Metastatic Non-Small-Cell Lung Cancer. J. Clin. Oncol. 2011, 30, 394-400, doi:10.1200/JCO.2011.35.7996.

64. Wright, A.A.; Zhang, B.; Ray, A.; Mack, J.W.; Trice, E.; Balboni, T.; Mitchell, S.L.; Jackson, V.A.; Block, S.D.; Maciejewski, P.K.; et al. Associations between End-of-Life Discussions, Patient Mental Health, Medical Care near Death, and Caregiver Bereavement Adjustment. JAMA 2008, 300, 1665-1673, doi:10.1001/jama.300.14.1665.

65. Granek, L.; Krzyzanowska, M.K.; Tozer, R.; Mazzotta, P. Oncologists' Strategies and Barriers to Effective Communication about the End of Life. J. Oncol. Pract. 2013, 9, e129-135, doi:10.1200/JOP.2012.000800.

66. Robinson, T.M.; Alexander, S.C.; Hays, M.; Jeffreys, A.S.; Olsen, M.K.; Rodriguez, K.L.; Pollak, K.I.; Abernethy, A.P.; Arnold, R.; Tulsky, J.A. Patient-Oncologist Communication in Advanced Cancer: Predictors of Patient Perception of Prognosis. Support. Care Cancer Off. J. Multinatl. Assoc. Support. Care Cancer 2008, 16, 1049-1057, doi:10.1007/s00520-007-0372-2.

67. Daugherty, C.K.; Hlubocky, F.J. What Are Terminally Ill Cancer Patients Told about Their Expected Deaths? A Study of Cancer Physicians' Self-Reports of Prognosis Disclosure. J. Clin. Oncol. Off. J. Am. Soc. Clin. Oncol. 2008, 26, 5988-5993, doi:10.1200/JCO.2008.17.2221.

68. Sullivan, A.M.; Lakoma, M.D.; Matsuyama, R.K.; Rosenblatt, L.; Arnold, R.M.; Block, S.D. Diagnosing and Discussing Imminent Death in the Hospital: A Secondary Analysis of Physician Interviews. J. Palliat. Med. 2007, 10, 882-893, doi:10.1089/jpm.2007.0189.

69. Ledoux, M.; Rhondali, W.; Monnin, L.; Thollet, C.; Gabon, P.; Filbet, M. [Advanced directives: nurses' and physicians' representations in 2012]. Bull. Cancer (Paris) 2013, 100, 941-945, doi:10.1684/bdc.2013.1817.

70. Keating, N.L.; Landrum, M.B.; Rogers, S.O.; Baum, S.K.; Virnig, B.A.; Huskamp, H.A.; Earle, C.C.; Kahn, K.L. Physician Factors Associated with Discussions about End-of-Life Care. Cancer 2010, 116, 998-1006, doi:10.1002/cncr.24761.

71. Hubert, S.; Wainschtein, S.; Hugues, A.; Schimpf, C.; Degroote, T.; Tiercelet, K.; Tran, M.; Bruel, C.; Philippart, F.; REQUIEM group (REQUIEM: Research/Reflexion on End of life support QUality In Everyday Medical practice) Advance Directives in France: Do Junior General Practitioners Want to Improve Their Implementation and Usage? A Nationwide Survey. BMC Med. Ethics 2019, 20, 19, doi:10.1186/s12910-019-0358-x. 
72. Almack, K.; Cox, K.; Moghaddam, N.; Pollock, K.; Seymour, J. After You: Conversations between Patients and Healthcare Professionals in Planning for End of Life Care. BMC Palliat. Care 2012, 11, 15, doi:10.1186/1472-684X-11-15.

73. The, A.M.; Hak, T.; Koëter, G.; van der Wal, G. Collusion in Doctor-Patient Communication about Imminent Death: An Ethnographic Study. West. J. Med. 2001, 174, 247-253, doi:10.1136/ewjm.174.4.247.

74. Barnes, K.A.; Barlow, C.A.; Harrington, J.; Ornadel, K.; Tookman, A.; King, M.; Jones, L. Advance Care Planning Discussions in Advanced Cancer: Analysis of Dialogues between Patients and Care Planning Mediators. Palliat. Support. Care 2011, 9, 73-79, doi:10.1017/S1478951510000568.

75. Sahm, S.; Will, R.; Hommel, G. What Are Cancer Patients' Preferences about Treatment at the End of Life, and Who Should Start Talking about It? A Comparison with Healthy People and Medical Staff. Support. Care Cancer Off. J. Multinatl. Assoc. Support. Care Cancer 2005, 13, 206-214, doi:10.1007/s00520-004-0725-z.

76. Freedman, B. Offering Truth: One Ethical Approach to the Uninformed Cancer Patient. Arch. Intern. Med. 1993, 153, 572-576, doi:10.1001/archinte.1993.00410050012003.

77. Lamont, E.B.; Siegler, M. Paradoxes in Cancer Patients' Advance Care Planning. J. Palliat. Med. 2000, 3, 27-35, doi:10.1089/jpm.2000.3.27.

78. Robinson, C.A.; Fyles, G.; McKenzie, M. Oncologist Experience Implementing Goals of Care Discussions in Everyday Ambulatory Oncology Practice: Implications for Education. J. Cancer Educ. Off. J. Am. Assoc. Cancer Educ. 2017, 32, 301-307, doi:10.1007/s13187-015-0915-z.

79. Boyd, K.; Mason, B.; Kendall, M.; Barclay, S.; Chinn, D.; Thomas, K.; Sheikh, A.; Murray, S.A. Advance Care Planning for Cancer Patients in Primary Care: A Feasibility Study. Br. J. Gen. Pract. J. R. Coll. Gen. Pract. 2010, 60, e449-458, doi:10.3399/bjgp10X544032.

80. Fu, S.; Barber, F.D.; Naing, A.; Wheler, J.; Hong, D.; Falchook, G.; Piha-Paul, S.; Tsimberidou, A.; Howard, A.; Kurzrock, R. Advance Care Planning in Patients with Cancer Referred to a Phase I Clinical Trials Program: The MD Anderson Cancer Center Experience. J. Clin. Oncol. Off. J. Am. Soc. Clin. Oncol. 2012, 30, 2891-2896, doi:10.1200/JCO.2011.38.0758.

81. Robinson, C.A. “Our Best Hope Is a Cure." Hope in the Context of Advance Care Planning. Palliat. Support. Care 2012, 10, 75-82, doi:10.1017/S147895151100068X.

82. Murray, L.; Butow, P.N.; White, K.; Kiernan, M.C.; D'Abrew, N.; Herz, H. Advance Care Planning in Motor Neuron Disease: A Qualitative Study of Caregiver Perspectives. Palliat. Med. 2016, 30, 471-478, doi:10.1177/0269216315613902.

83. Temel, J.S.; Shaw, A.T.; Greer, J.A. Challenge of Prognostic Uncertainty in the Modern Era of Cancer Therapeutics. J. Clin. Oncol. Off. J. Am. Soc. Clin. Oncol. 2016, 34, 3605-3608, doi:10.1200/JCO.2016.67.8573.

84. Helft, P.R. Necessary Collusion: Prognostic Communication with Advanced Cancer Patients. J. Clin. Oncol. Off. J. Am. Soc. Clin. Oncol. 2005, 23, 3146-3150, doi:10.1200/JCO.2005.07.003.

85. Laryionava, K.; Heußner, P.; Hiddemann, W.; Winkler, E.C. Framework for Timing of the Discussion about Forgoing Cancer-Specific Treatment Based on a Qualitative Study with Oncologists. Support. Care Cancer Off. J. Multinatl. Assoc. Support. Care Cancer 2015, 23, 715-721, doi:10.1007/s00520-014-2416-8.

86. Barnes, K.; Jones, L.; Tookman, A.; King, M. Acceptability of an Advance Care Planning Interview Schedule: A Focus Group Study. Palliat. Med. 2007, 21, 23-28, doi:10.1177/0269216306073638.

87. Díaz-Montes, T.P.; Johnson, M.K.; Giuntoli, R.L.; Brown, A.J. Importance and Timing of End-of-Life Care Discussions among Gynecologic Oncology Patients. Am. J. Hosp. Palliat. Care 2013, 30, 59-67, doi:10.1177/1049909112444156.

88. Fried, T.R.; O'Leary, J.R. Using the Experiences of Bereaved Caregivers to Inform Patient- and Caregiver-Centered Advance Care Planning. J. Gen. Intern. Med. 2008, 23, 1602-1607, doi:10.1007/s11606-008-0748-0.

89. Walczak, A.; Henselmans, I.; Tattersall, M.H.N.; Clayton, J.M.; Davidson, P.M.; Young, J.; Bellemore, F.A.; Epstein, R.M.; Butow, P.N. A Qualitative Analysis of Responses to a Question Prompt List and Prognosis and End-of-Life Care Discussion Prompts Delivered in a Communication Support Program. Psychooncology. 2015, 24, 287-293, doi:10.1002/pon.3635.

90. Goelz, T.; Wuensch, A.; Stubenrauch, S.; Ihorst, G.; de Figueiredo, M.; Bertz, H.; Wirsching, M.; Fritzsche, K. Specific Training Program Improves Oncologists' Palliative Care Communication Skills in a Randomized Controlled Trial. J. Clin. Oncol. Off. J. Am. Soc. Clin. Oncol. 2011, 29, 3402-3407, doi:10.1200/JCO.2010.31.6372.

91. Fournier, V.; Berthiau, D.; Kempf, E.; d'Haussy, J. [Are advance directives useful for doctors and what for?]. Presse Medicale Paris Fr. 1983 2013, 42, e159-169, doi:10.1016/j.lpm.2012.09.027.

92. Biola, H.; Sloane, P.D.; Williams, C.S.; Daaleman, T.P.; Zimmerman, S. Preferences versus Practice: Life-Sustaining Treatments in Last Months of Life in Long-Term Care. J. Am. Med. Dir. Assoc. 2010, 11, 42-51, doi:10.1016/j.jamda.2009.07.005.

93. Bomba, P.A.; Kemp, M.; Black, J.S. POLST: An Improvement over Traditional Advance Directives. Cleve. Clin. J. Med. 2012, 79, 457-464, doi:10.3949/ccjm.79a.11098.

94. Lamas, D.; Panariello, N.; Henrich, N.; Hammes, B.; Hanson, L.C.; Meier, D.E.; Guinn, N.; Corrigan, J.; Hubber, S.; Luetke-Stahlman, H.; et al. Advance Care Planning Documentation in Electronic Health Records: Current Challenges and Recommendations for Change. J. Palliat. Med. 2018, 21, 522-528, doi:10.1089/jpm.2017.0451.

95. Brinkman-Stoppelenburg, A.; Rietjens, J.A.C.; van der Heide, A. The Effects of Advance Care Planning on End-of-Life Care: A Systematic Review. Palliat. Med. 2014, 28, 1000-1025, doi:10.1177/0269216314526272.

96. Johnstone, M.-J.; Kanitsaki, O. Ethics and Advance Care Planning in a Culturally Diverse Society. J. Transcult. Nurs. Off. J. Transcult. Nurs. Soc. 2009, 20, 405-416, doi:10.1177/1043659609340803.

97. Johnson, S.; Butow, P.; Kerridge, I.; Tattersall, M. Advance Care Planning for Cancer Patients: A Systematic Review of Perceptions and Experiences of Patients, Families, and Healthcare Providers. Psychooncology. 2016, 25, 362-386, doi:10.1002/pon.3926. 
98. Huang, H.-L.; Tsai, J.-S.; Yao, C.-A.; Cheng, S.-Y.; Hu, W.-Y.; Chiu, T.-Y. Shared Decision Making with Oncologists and Palliative Care Specialists Effectively Increases the Documentation of the Preferences for Do Not Resuscitate and Artificial Nutrition and Hydration in Patients with Advanced Cancer: A Model Testing Study. BMC Palliat. Care 2020, 19, 17, doi:10.1186/s12904-020-0521-7.

99. You, J.J.; Downar, J.; Fowler, R.A.; Lamontagne, F.; Ma, I.W.Y.; Jayaraman, D.; Kryworuchko, J.; Strachan, P.H.; Ilan, R.; Nijjar, A.P.; et al. Barriers to Goals of Care Discussions with Seriously Ill Hospitalized Patients and Their Families: A Multicenter Survey of Clinicians. JAMA Intern. Med. 2015, 175, 549-556, doi:10.1001/jamainternmed.2014.7732.

100. Temel, J.S.; Greer, J.A.; Gallagher, E.R.; Jackson, V.A.; Lennes, I.T.; Muzikansky, A.; Park, E.R.; Pirl, W.F. Electronic Prompt to Improve Outpatient Code Status Documentation for Patients With Advanced Lung Cancer. J. Clin. Oncol. 2013, 31, 710-715, doi:10.1200/JCO.2012.43.2203.

101. Goswami, P.; Mistric, M.; Diane Barber, F. Advance Care Planning: Advanced Practice Provider-Initiated Discussions and Their Effects on Patient-Centered End-of-Life Care. Clin. J. Oncol. Nurs. 2020, 24, 81-87, doi:10.1188/20. CJON.81-87.

102. Eliott, J.A.; Olver, I.N. Perceptions of “Good Palliative Care" Orders: A Discursive Study of Cancer Patients' Comments. J. Palliat. Med. 2003, 6, 59-68, doi:10.1089/10966210360510127.

103. Buiar, P.G.; Goldim, J.R. Barriers to the Composition and Implementation of Advance Directives in Oncology: A Literature Review. ecancermedicalscience 2019, 13, doi:10.3332/ecancer.2019.974. 